\title{
Without Accessible Primary Care, We Are "Dangerously Unprepared" for the Next Pandemic
}

Polio, yellow fever, diphtheria, tetanus, pertussis and other deadly or debilitating diseases are routinely prevented and controlled with vaccines-when and where they are accessible.[1] Characterized as one of the most effective public health interventions ever available, WHO estimates that immunization saves four to five million lives every year.[2]

And yet. After another year working to contain the worst pandemic in living memory, evidence-based science and the life-saving vaccines it produces struggle to be heard above the din of bad (and fake) news. Anti-vaxxers and -maskers grab headlines; more transmissible variants travel the globe; vaccine inequity places everyone at higher risk; and the most economically vulnerable plumb even darker depths.

WHO set a global target of $40 \%$ COVID-19 vaccination coverage by the end of 2021 and $70 \%$ by mid-2022. The first target was not met. The second target will not be met. In the meantime, the hard, tragic reality is that many more people will become sick and some will die-needlessly.

In the United States, despite the availability of vaccines proven to prevent severe COVID-19, hospitalizations and deaths, just over half of youngsters aged 12-18 years are fully vaccinated. [3] It's a woeful statistic given that a recent study by the Centers for Disease Control and Prevention (CDC) found the Pfizer vaccine for those aged $12-17$ prevented $94 \%$ of hospitalizations and $98 \%$ of ICU remittances.[4] The vaccine has been available since May 2021. According to the same study, nearly all the teenagers admitted to ICUs in 31 pediatric hospitals around the country with COVID-19 were unvaccinated; seven of them died. Each of these deaths might have been prevented.

Meanwhile, vaccine inequity slams the more vulnerable precisely when they are most vulnerable: by the end of December 2021, only $7 \%$ of people in low-income countries had received even a single dose of a COVID-19 vaccine, an unconscionable statistic. [5] Viruses like SARS-CoV-2 take swift advantage of the unvaccinated to spread and mutate into deadlier and/or more transmissible variants-exactly what happened with delta and is happening now with omicron. In the last week of December alone, infections increased by $50 \%$ and deaths by $11 \%$ in the Americas, according to $\mathrm{PAHO},[6]$ while the USA registered a record 1.35 million new cases in a single day in January.[7]

Whether you are unwilling or unable to get a COVID-19 vaccine, the outcome is the same: more infections, more severe cases and more deaths.

It is no secret why vaccination rates are so uneven and infections soaring. Inadequate and inequitable vaccine strategies by and within individual countries have led to hoarding millions of doses, compounded by poorly-coordinated mechanisms for administering them. Meanwhile, distrust of health authorities and their messaging - too often muddled or poorly communicated-weakens adherence to preventive measures like masking and distancing. Indeed, the CDC has come under fire for issuing "confusing and flawed" guidelines that fail to communicate health policy clearly.[8] Misinformation, conspiracy theories and false news flourish in this environment, fueling vaccine hesitancy, mistrust of health authorities and anti-science in general. The world's health professionals are left to deal with the fallout-until they burn out, retire or are themselves infected, deepening the crisis.

Effectively tackling these problems is rife with hurdles. Moreover, necessary system-wide initiatives are easy targets for detractors. Such an overhaul is branded too costly. Too complicated. Too cumbersome. Competing interests too entrenched to bother. But what this argument conveniently ignores is the one strategy that has proven effective, both in terms of health outcomes and return on investment: primary health care.

According to a recent report by the US National Academies of Sciences: "high-quality primary care is the foundation of a high-functioning health care system and is critical for...enhancing patient experience, improving population health [and] reducing costs."[9] Nevertheless, family physicians and nurses, the foundation of primary care, were initially left out of the nation's COVID-19 vaccine strategy. Instead, drugstores were tasked with administering the majority of vaccines and diagnostic kits, while community primary care practices-where routine and childhood vaccines, along with preventive and other care is provided to patients who have an ongoing relationship with their doctors-were sidelined. This adversely affected rapid, equitable distribution of COVID-19 vaccines, especially in rural, African-American and Hispanic communities. The fact that it was very difficult to get vaccinated against COVID-19 at a doctor's office in the United States contributed to vaccine hesitancy by not involving the health professionals most trusted by their patients: primary care providers.[10]

In Cuba, equitable vaccination, delivered via a strong, coordinated primary health care system is a cornerstone of the country's population health strategy and is helping contain COVID-19. Family doctors, nurses and medical students went door-to-door early in the pandemic to educate families and screen for symptoms. Community-based polyclinics and their staffs were accredited to participate in clinical trials for Cuba's vaccine candidates. And thousands of family doctors and nurses received training and accreditation to vaccinate young and old in their catchment areas, making for a streamlined rollout.

As of this writing, nearly $90 \%$ of the Cuban population is fully vaccinated against COVID-19-including infants as young as two-with a triple-dose schedule using vaccines developed and produced on the island (see our exclusives this issue with Rinaldo Puga, Principal Investigator for the vaccines' pediatric trials and Verena Muzio, Director of Clinical Research at the Genetic Engineering and Biotechnology Center in Havana). The result is a $0.83 \%$ fatality rate (compared to $2.03 \%$ in the Americas and $1.69 \%$ worldwide), reinforcing public trust in science, vaccines and the professionals administering them.[11]

This trust was hard won over decades, built on a three-pronged strategy of community-based primary care, universal access and science. Despite COVID-19 and the resulting economic blow 


...the key lesson from
COVID-19 that must
be implemented
urgently is building
accessible, equitable
and sustainable primary
healthcare systems that
respond to science

Vaccines and related public health measures can contain the current pandemic, but what about long COVID, heart and lung damage, chronic kidney impairment and other possible lasting health effects for convalescents - to say nothing of the mental health toll and psychological distress many are experiencing? What about the next pandemic, which experts warn could be more lethal than COVID-19 and for which the world is "dangerously unprepared?" Rather than "fall back into the decades-long cycle of panic and neglect that will leave the world at grave risk for inevitable future public health threats,"[12] the key lesson from COVID-19 that must be implemented urgently is building accessible, equitable and sustainable primary healthcare systems that respond to science. For millions, it's already too late. 1 -

\section{The Editors}

\section{NOTES \& REFERENCES}

1. According to $\mathrm{WHO}$, an estimated 23 million children under the age of one year did not receive basic vaccines in 2020 , the highest number since 2009. Many, but not all, of these infants are in low- and middle-income countries. See: https://www.who.int/news-room/fact-sheets/detail/immunization-coverage
2. World Health Organization [Internet]. Geneva: World Health Organization; c2022. Immunization; 2019 Dec 5 [cited 2022 Jan 19]; [about 2 p.]. Available at: https://www.who.int/news-room/facts-in-pictures/detail/immunization

3. Tanner L, Stobbe M. Hospitalisations of kids too young for COVID shots soar in the US. Sydney Morning Herald [Internet]. 2022 Jan 8 [cited 2022 Jan 18]; Coronavirus pandemic:[about 2 p.]. Available at: https://www.smh.com.au/ world/north-america/hospitalisations-of-kids-too-young-for-covid-shots-soar -in-the-us-20220108-p59mr0.html

4. Edwards KM. Sparing of severe Covid-19 in vaccinated adolescents. NEJM [Internet]. 2022 Jan 12 [cited 2022 Jan 19]; [about 2 p.]. DOI: 10.1056/NEJMe2118471. Available at: https://www.nejm.org/doi/full/10.1056/NEJMe2118471

5. Rouw A., Wexler A., Kates J. A year of vaccine inequity. KFF [Internet]. 2021 Dec 22 [cited 2022 Jan 18]; [about 2 p.]. Available at: https://www.kff.org/glo bal-health-policy/slide/a-year-of-vaccine-inequity/

6. Pan American Health Organization [Internet]. Washington, D.C.: Pan American Health Organization; c2022. News. Aumenta 50\% los casos de COVID-19 en la última semana en las Ámericas; 2021 Dec 29 [cited 2022 Jan 19]; [about 2 p.]. Available at: https://www.paho.org/es/noticias/29-12-2021-aumentan -50-casos-covid-19-ultima-semana-americas. Spanish.

7. Shumaker L. U.S. reports 1.35 million COVID-19 cases in a day, shattering global record [Internet]. London: Reuters; 2022 Jan 11 [cited 2022 Jan 18]; [about 2 p.]. Available at: https://www.reuters.com/business/healthcare -pharmaceuticals/us-reports-least-11-mln-covid-cases-day-shattering-global -record-2022-01-11/

8. Toy S. CDC Director aims to improve Covid-19 messaging, data collection Wall Street Journal [Internet]. 2022 Jan 17 [cited 2022 Jan 19]; [about 3 p.]. Available at: https://www.wsj.com/articles/cdc-director-aims-to-improve-covid -19-messaging-data-collection-11642429801

9. National Academies of Sciences, Engineering, and Medicine 2021. Implementing High-Quality Primary Care: Rebuilding the Foundation of Health Care [Internet]. Washington, D.C.: The National Academies Press. https://doi.org/10.172 26/25983

10. American Academy of Family Physicians. Leveraging primary care physicians to accelerate COVID-19 vaccination. Letter to: Jeffrey Zients (Coordinator of the COVID-19 Response and Counselor to the President (The White House). 2021 Jan 29 [cited Jan 21]. 3 leafs. Available at: https://www.aafp.org/dam/ AAFP/documents/advocacy/prevention/vaccines/LT-WH-Recommendation slmproveCOVIDVaccination-012921.pdf

11. Ministry of Public Health (CU). Coronavirus en Cuba: Parte de cierre del día 18 de enero a las 12 de la noche [Internet]. 2022 Jan 19 [cited 2022 Jan 19]; [about 1 p.]. Available at: https://salud.msp.gob.cu. Spanish.

12. Morris C. We're 'dangerously unprepared' for future pandemics even after COVID, global study warns. Fortune [Internet]. 2021 Dec 8 [cited 2022 Jan 19]; [about 1 p.]. Available at: https://fortune.com/2021/12/08/world-dangerously 